\title{
Prognostic impact of breast cancer subtypes in elderly patients
}

\author{
E. S. Bergen ${ }^{1,2} \cdot$ C. Tichy ${ }^{1,2} \cdot$ A. S. Berghoff ${ }^{1,2} \cdot$ M. Rudas ${ }^{1,3} \cdot$ P. Dubsky ${ }^{1,4}$. \\ Z. Bago-Horvath ${ }^{1,3}$ - R. M. Mader ${ }^{1,2} \cdot$ R. Exner ${ }^{1,4} \cdot$ M. Gnant ${ }^{1,4}$ - C. C. Zielinski ${ }^{1,2}$. \\ G. G. Steger ${ }^{1,2} \cdot$ M. Preusser ${ }^{1,2} \cdot$ R. Bartsch ${ }^{1,2}$
}

Received: 9 January 2016/Accepted: 5 April 2016/Published online: 23 April 2016

(c) The Author(s) 2016. This article is published with open access at Springerlink.com

\begin{abstract}
We aimed to analyse the impact of breast cancer (BC) subtypes on the clinical course of disease with special emphasis on the occurrence of brain metastases (BM) and outcome in an elderly BC population. A total number of 706 patients $\geq 65$ years receiving treatment for BC from 2007 to 2011 were identified from a BC database. 62 patients diagnosed with DCIS and 73 patients with incomplete datasets were excluded, leaving 571 patients for this analysis. Patient characteristics, biological tumour subtypes, and clinical outcome including overall survival (OS) were obtained by retrospective chart review. 380/571 $(66,5 \%)$ patients aged $65-74$ years were grouped among the young-old, 182/571 (31.9\%) patients aged $75-84$ years among the old-old, and 29/571 (5.1\%) patients aged $\geq 85$ years among the oldest-old. 392/571 (68.8\%) patients presented with luminal BC, 119/571 (20.8\%) with HER2positive, and 59/571 (10.3\%) with triple-negative BC (TNBC). At 38 months median follow-up, 115/571 (20.1\%) patients presented with distant recurrence. A higher recurrence rate was observed in the HER2-positive subtype (43/119 (36.1\%)), as compared to TNBC (15/59
\end{abstract}

\section{E. S. Bergen}

elisabeth.bergen@meduniwien.ac.at

$\triangle$ R. Bartsch

rupert.bartsch@meduniwien.ac.at

1 Comprehensive Cancer Center, Vienna, Austria

2 Clinical Division of Oncology, Department of Medicine 1, Medical University of Vienna, Vienna, Austria

3 Department of Pathology, Medical University of Vienna, Vienna, Austria

4 Department of Surgery, Medical University of Vienna, Vienna, Austria
$(25.4 \%))$ and luminal BC (57/392 (14.5\%); $p<0.001)$. $\mathrm{BM}$ were detected at a significantly higher rate in HER2positive BC patients $(9 / 119$ (7.6\%)), as compared to TNBC (2/59 (3.4\%)) and luminal BC patients $(6 / 392$ $(1.5 \%) ; p=0.003)$. Diagnosis of metastatic disease (HR 7.7; $95 \%$ CI 5.2-11.4; $p<0.001$ ) as well as development of BM (HR 3.5; $95 \%$ CI 1.9-6.4; $p<0.001$ ) had a significantly negative impact on OS in a time-dependent covariate cox regression model. In contrast to younger BC patients, outcome in this large cohort of elderly patients suggests that HER2-positive disease-not TNBC-featured the most aggressive clinical course with the highest rates of metastatic spread and BM. In-depth analysis regarding a potentially distinct biology of TNBC in elderly is therefore warranted.

Keywords Brain metastases - Elderly patients .

Metastatic breast cancer - HER2-positive breast cancer .

Risk factors · Triple-negative disease

\section{Introduction}

Breast cancer (BC) in elderly women is a major challenge for modern health care systems; today, approximately $40 \%$ of all new BC cases in developed countries are diagnosed in women 65 years of age and older [1]. Elderly patients are less fit to undergo standard treatment and under-representation in clinical trials results in a lack of evidence-based treatment recommendations [2,3].

In addition to standard parameters such as clinical stage and tumour biology, several age-specific aspects have to be considered in the process of decision making in elderly patients. Patients beyond the age of 70 have a median number of three comorbidities [4], decreased renal [5], and 
bone marrow function [6], and physiological changes associated with age such as increase of body fat, reduction of body water, reduced albumin levels, and reduced bowel motility. These factors result in altered pharmacokinetics of antineoplastic drugs and may further increase treatmentrelated toxicity $[7,8]$. In addition, the number of comorbidities correlates with number of drugs taken daily; indeed, a patient of 70-80 years of age receives eight to nine tablets per day [9], thereby increasing the risk for relevant drug-drug interactions.

BC in elderly women is postulated to have a less aggressive biology as indicated by a higher rate of hormone-receptor-positive tumours, lower grading and lower proliferation rate as compared to younger patients [10]. On the other hand, tumour stage at primary diagnosis is commonly more advanced [11] due to lack of participation in screening programmes; furthermore, even in elderly women, a relevant number of patients will present with tumours of aggressive biology with HER2-positive or triple-negative phenotype [12].

In HER2-positive $\mathrm{BC}$, a higher rate of brain metastases (BM) and shorter BM-free survival (BMFS) was observed as compared to luminal disease [13, 14]; similar results were reported in triple-negative BC (TNBC) patients as well [15]. Of note, despite a recent surge of interest in BC in elderly, limited data are available with regard to specific BC subtypes. Therefore, we aimed to investigate the impact of subtypes on the clinical course of disease in an elderly $\mathrm{BC}$ population with a special emphasis on BM.

\section{Patients and methods}

Elderly patients as defined by age $\geq 65$ years at first $\mathrm{BC}$ diagnosis receiving treatment at the Medical University of Vienna between 2007 and 2011 were identified from a BC database. Information relating to patient demographics, case history, and survival were collected by retrospective chart review. This study was conducted in accordance with the ethical regulations of the Medical University of Vienna and the approval by the local ethics committee was obtained.

All patients were managed by a dedicated team of BC specialists at an academic breast centre; treatment decisions were taken in an interdisciplinary tumour conference. Treatment was performed according to best clinical evidence and according to current standard of care. No routine brain imaging as screening for central-nervous system (CNS) involvement was performed. Brain imaging with MRI was only performed when clinically indicated due to neurological symptoms.

\section{Hormone receptor and HER2-status}

Oestrogen-receptor (ER) and progesterone-receptor (PR) status were assessed by immunohistochemistry (ER $\alpha$ antibody, clone 1D5, Dako A/S, Glostrup, Denmark; and PgR antibody, Dako A/S, Glostrup, Denmark); hormone-receptor expression was estimated as the percentage of positively stained tumour cells. Results were given as $1+, 2+$, and $3+$ positive or negative staining, with a cut-off value of $<10 \%$ positive tumour cells [16]. HER2-status was assessed by immunohistochemistry (Herceptest ${ }^{\circledR}$; Dako A/S, Glostrup, Denmark) and dual colour fluorescent in situ hybridization (FISH; PathVision ${ }^{\circledR}$ Her2 DNA probe kit, Vysis Inc., Downers Grove, IL, USA). Tumours were classified as HER2-positive if they had a staining intensity of $3+$ on the Herceptest ${ }^{\circledR}$; tumours with staining intensity of $2+$ were tested by FISH for HER2 DNA amplification [17].

\section{BC subtypes}

BC subtypes were defined as previously described according to the results of immunohistochemical analysis and FISH: Tumour specimens presenting hormone-receptor expression in at least $10 \%$ of cancer cells without HER2-receptor overexpression were defined as belonging to the luminal subtype. HER2-positive BC was defined by strong membranous overexpression of HER2 (IHC 3+) and/or amplification of the $H E R 2 / n e u$ gene. TNBC was defined by the absence of steroidreceptor expression as well as HER2 overexpression [18, 19].

\section{Statistical analysis}

Overall survival (OS) was defined as interval from first diagnosis of BC until death and estimated with the KaplanMeier product limit method. To test for differences between survival curves, the log-rank test was used; to test for impact of BM and metastases on OS, a time-dependent covariate cox regression model was used. For correlation of two parameters, Fisher's exact test or $\chi^{2}$ test was used as appropriate. Correlation analysis was performed for subtypes and age groups, metastatic recurrence, and BM. Twotailed $p$ values $<0.05$ were considered to indicate statistical significance. All statistics were calculated using statistical package for the social sciences $\left(\right.$ SPSS $\left.^{\circledR}\right) 21.0$ software (SPSS Inc., Chicago, IL, USA).

\section{Results}

\section{Patient characteristics}

A total number of 706 patients $\geq 65$ years receiving treatment for breast cancer from 2007 to 2011 were identified 
from a breast cancer database. 62 patients diagnosed with DCIS and 73 patients with incomplete data were excluded, leaving 571 patients for this analysis (Fig. 1). Median age at primary diagnosis of $\mathrm{BC}$ was 73 years (range 65-94 years); three hundred eighty/571 (66.5\%) patients aged 65-74 years were grouped among the young-old, $182 / 571$ (31.9\%) patients aged 75-84 years among the old-old, and 29/571 (5.1\%) patients aged $\geq 85$ years among the oldest-old, respectively.

456/571 (79.9\%) patients had steroid-receptor-positive disease (ER-positive, both non-HER2 and HER2-positive) and 119/571 (20.8\%) HER2 overexpression or HER2/neu gene amplification (both ER-positive and ER-negative); 128/571 (22.4\%) patients received adjuvant chemotherapy for early BC, while 45/571 (7.9\%) patients were diagnosed with primary metastatic disease. Metachronous metastases were detected in 115/571 (20.1\%) patients during their respective course of disease; in patients with metastatic disease, occurrence of visceral metastases either with or without non-visceral metastases was observed in 76/115 $(66.1 \%)$ of the patients and non-visceral only disease in $39 / 115(33.9 \%)$ of the patients. Characteristics of the overall patient population are summarized in Table 1.

\section{The impact of BC subtypes on the clinical course of disease}

392/571 (68.8\%) patients presented with luminal BC (luminal non-HER2), 119/571 (20.8\%) with HER2-positive BC (both luminal and non-luminal disease, HER2-positive) and 59/571 (10.3\%) with TNBC. No correlation was

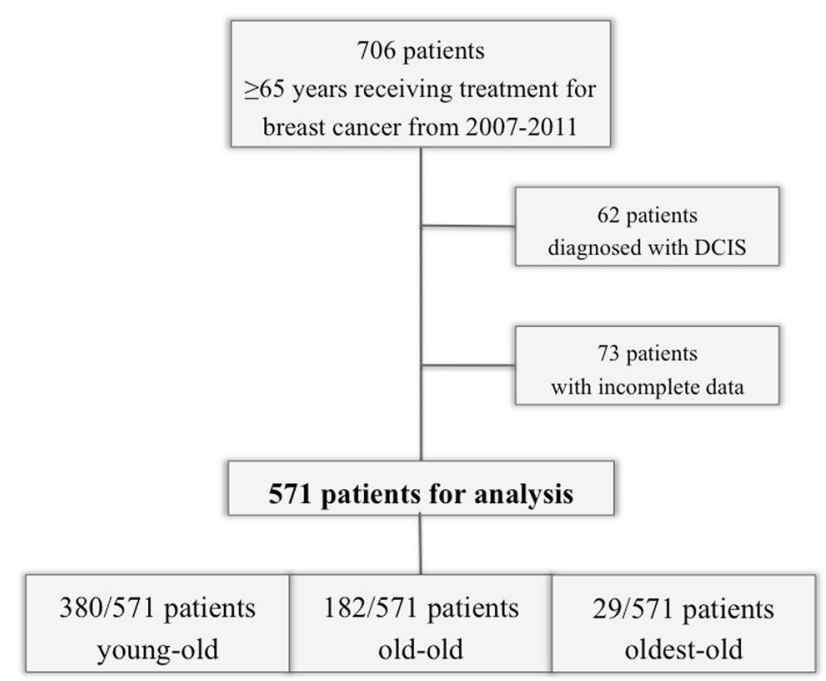

Fig. 1 CONSORT diagram: a total number of 706 patients $\geq 65$ years receiving treatment for breast cancer from 2007 to 2011 were identified from a breast cancer database. 62 patients diagnosed with DCIS and 73 patients with incomplete data were excluded, leaving 571 patients for this analysis observed between frequency of BC subtypes and age groups ( $p>0.05 ; \chi^{2}$ test).

At a median follow-up of 38 months (range 0-204), $115 / 571(20.1 \%)$ patients presented with metachronous metastatic recurrence. The highest recurrence rate was observed in HER2-positive BC disease (43/119 (36.1\%)), followed by TNBC (15/59 (25.4\%)) and luminal BC (57/ $392(14.5 \%) ; p<0.001 ; \chi^{2}$ test). Within every subtype, visceral metastases were more often observed than nonvisceral metastases ( $p>0.05 ; \chi^{2}$ test). The ratio of visceral metastases was the highest in HER2-positive followed by triple-negative and luminal metastasized disease, but this difference did not reach statistical significance (74.4 vs. 73.3 vs. $57.9 \% ; p>0.05 ; \chi^{2}$ test).

$17 / 571$ (3\%) patients were diagnosed with BM during their respective course of disease. BM were significantly more often observed in HER2-positive BC patients 9/119 (7.6\%) as compared to TNBC 2/59 (3.4\%) and luminal BC patients $\left[6 / 392(1.5 \%) ; p=0.003 ; \chi^{2}\right.$ test]. Also, significantly more patients in the group with BM had HER2-positive disease 9/17 (52.9\%) than in patients without BM [110/554 (19.9\%); $p=0.001 ; \chi^{2}$ test]. In contrast, no difference was observed in patients with triplenegative disease with or without BM [2/17 (11.8\%) vs. 58/554 (10.5\%); $p>0.05 ; \chi^{2}$ test]. Table 2 lists patients' characteristics according to BC subtypes.

\section{Impact of age group on clinical course of disease}

Distant metastases were most frequently observed in the young-old group $(76 / 115 ; 66.1 \%)$ followed by the old-old $(37 / 115 ; 32.2 \%)$ and the oldest-old group $(2 / 115 ; 1.7 \%)$. No significant differences in the pattern of metastatic spread were observed between the different age groups, although a numerically higher frequency of visceral metastases was recorded in patients of the old-old and oldest groups. With regard to BM, 13/17 with BM (76.5 \%) were from the young-old group, while the remaining four $(23.5 \%)$ were from the old-old group. No BM were observed among the oldest-old patients.

Cardiovascular disease was the most frequently reported comorbidity [382/571 (66.9\%)]; diabetes was evident in $179 / 571(31.3 \%)$ patients and renal impairment in 38/571 $(6.7 \%)$ patients at first diagnosis of BC. Patients of the young-old group presented significantly more often with cardiovascular comorbidities $230 / 382(60.2 \%)$ as compared to patients of the old-old group 135/382 $(35.3 \%)$ and the oldest-old group $\left[17 / 382(4.5 \%) ; p=0.03 ; \chi^{2}\right.$ test], respectively. In contrast, renal impairment was significantly more frequently observed in patients of the oldold group $21 / 38(55.3 \%)$ compared to the young-old $14 / 38$ (36.8\%) and the oldest-old group $3 / 38$ (7.9 \%; $p=0.002$; $\chi^{2}$ test). No significant difference between age groups was 
Table 1 General patient's characteristics

\begin{tabular}{|c|c|c|}
\hline \multirow[t]{2}{*}{ Characteristics } & \multicolumn{2}{|c|}{ Entered patients $(n=571)$} \\
\hline & $n$ & $\%$ \\
\hline Median age at $\mathrm{BC}$ diagnosis (years) & 73 & \\
\hline Range & $65-94$ & \\
\hline \multicolumn{3}{|l|}{ Age groups } \\
\hline Young-old ( $\geq 65-74$ years) & 360 & 66.5 \\
\hline Old-old (75-84 years) & 182 & 31.9 \\
\hline Oldest-old ( $\geq 85$ years) & 29 & 5.1 \\
\hline Invasive ductal carcinoma & 383 & 67.1 \\
\hline Oestrogen-receptor positive & 456 & 79.9 \\
\hline Progesterone-receptor positive & 315 & 55.2 \\
\hline Stage IV at diagnosis & 45 & 7.9 \\
\hline Proliferation rate $\geq 20 \%$ & 233 & 40.8 \\
\hline p53-positive & 124 & 21.7 \\
\hline \multicolumn{3}{|l|}{ Subtypes } \\
\hline Luminal subtype & 393 & 68.8 \\
\hline Her2-positive subtype & 119 & 20.8 \\
\hline Triple-negative subtype & 59 & 10.3 \\
\hline Localized disease at primary diagnosis & 456 & 79.9 \\
\hline Metastatic recurrence during course of disease & 115 & 20.1 \\
\hline Visceral & 76 & 66.1 \\
\hline Non-visceral only & 39 & 33.9 \\
\hline Occurrence of BM during course of disease & 17 & 3 \\
\hline \multicolumn{3}{|l|}{ Adjuvant therapy } \\
\hline Chemotherapy & 128 & 22.4 \\
\hline Endocrine therapy & 352 & 61.6 \\
\hline Herceptin therapy & 30 & 5.3 \\
\hline Median OS from first diagnosis (months) & 93 & \\
\hline Range & $91-112$ & \\
\hline
\end{tabular}

Table 2 Patient's characteristics according to subtypes

\begin{tabular}{|c|c|c|c|c|c|c|c|}
\hline \multirow[t]{2}{*}{ Characteristics } & \multicolumn{2}{|c|}{ Luminal } & \multicolumn{2}{|c|}{ HER2 } & \multicolumn{2}{|c|}{ Triple neg } & \multirow[t]{2}{*}{$p$ value } \\
\hline & $n$ & $\%$ & $n$ & $\%$ & $n$ & $\%$ & \\
\hline Median age at diagnosis & \multicolumn{2}{|c|}{$\begin{array}{l}73 \text { years } \\
\text { (range 65-92) }\end{array}$} & \multicolumn{2}{|c|}{$\begin{array}{l}73 \text { years } \\
\text { (range 65-94) }\end{array}$} & \multicolumn{2}{|c|}{$\begin{array}{l}72 \text { years } \\
\text { (range 65-87) }\end{array}$} & 0.592 \\
\hline \multicolumn{8}{|l|}{ Age group } \\
\hline Young-old & 246 & 62.6 & 72 & 60.5 & 42 & 71.2 & \\
\hline Old-old & 129 & 32.8 & 41 & 34.5 & 12 & 20.3 & 0.276 \\
\hline Oldest-old & 18 & 4.6 & 6 & 5.0 & 5 & 8.5 & \\
\hline p53-positive & 54 & 13.7 & 37 & 31.1 & 33 & 55.9 & $<0.001$ \\
\hline Grade 3 & 69 & 17.6 & 60 & 50.4 & 35 & 59.3 & $<0.001$ \\
\hline Stage IV at first diagnosis & 21 & 5.3 & 18 & 15.1 & 6 & 10.2 & 0.009 \\
\hline Metastases & 57 & 14.5 & 43 & 36.1 & 15 & 25.4 & \\
\hline Visceral metastases & 33 & 57.9 & 32 & 74.4 & 11 & 73.3 & 0.184 \\
\hline Non-visceral & 24 & 42.1 & 11 & 25.6 & 4 & 26.7 & \\
\hline BM & 6 & 1.5 & 9 & 7.6 & 2 & 3.4 & 0.003 \\
\hline Overall survival from first diagnosis & \multicolumn{2}{|c|}{$\begin{array}{l}95 \text { months } \\
\text { (range 92-116) }\end{array}$} & \multicolumn{2}{|c|}{$\begin{array}{l}88 \text { months } \\
\text { (range 75-106) }\end{array}$} & \multicolumn{2}{|c|}{$\begin{array}{l}204 \text { months } \\
\text { (range 94-155) }\end{array}$} & 0.058 \\
\hline
\end{tabular}


observed with regard to diabetes; numerically, the highest rate was reported in the young-old group 104/179 (58.1\%) followed by the old-old group 68/179 (38.0\%) and the oldest-old group [7/179 (3.9\%]; $p>0.05 ; \chi^{2}$ test).

\section{Impact of BC subtypes and comorbidities on survival outcome}

OS in the entire patient population was 93 months (95\% CI, 91.44-111.88) and a significant impact of age groups on OS was observed: Median OS in the young-old group was 110 months (95\%CI, 105.55-136.20), as compared to 74 months (95\% CI, 71.22-93.61) among old-old and 35 months (95\% CI, 29.31-55.45) among oldest-old patients ( $p<0.001$, log-rank test) (Fig. 2).

In this population of elderly patients, only a non-significant association of BC subtypes with survival outcome was observed: Patients with luminal disease had 95 months median OS (95\% CI, 92.16-116.29), as compared to 88 months (95\% CI, 74.51-105.74) in patients with HER2-positive BC and 204 months $(95 \%$ CI, 93.52-155.14) in patients with TNBC ( $p=0.058$, log-rank test) (Fig. 3). Also, pattern of metastatic spread did not correlate significantly with the OS prognosis. Patients with visceral metastases had a median OS of 66 months (95\% CI, 68.65-99.12) compared to 74 months (71.80-109.88) in patients with non-visceral involvement $(p>0.05$, logrank test).

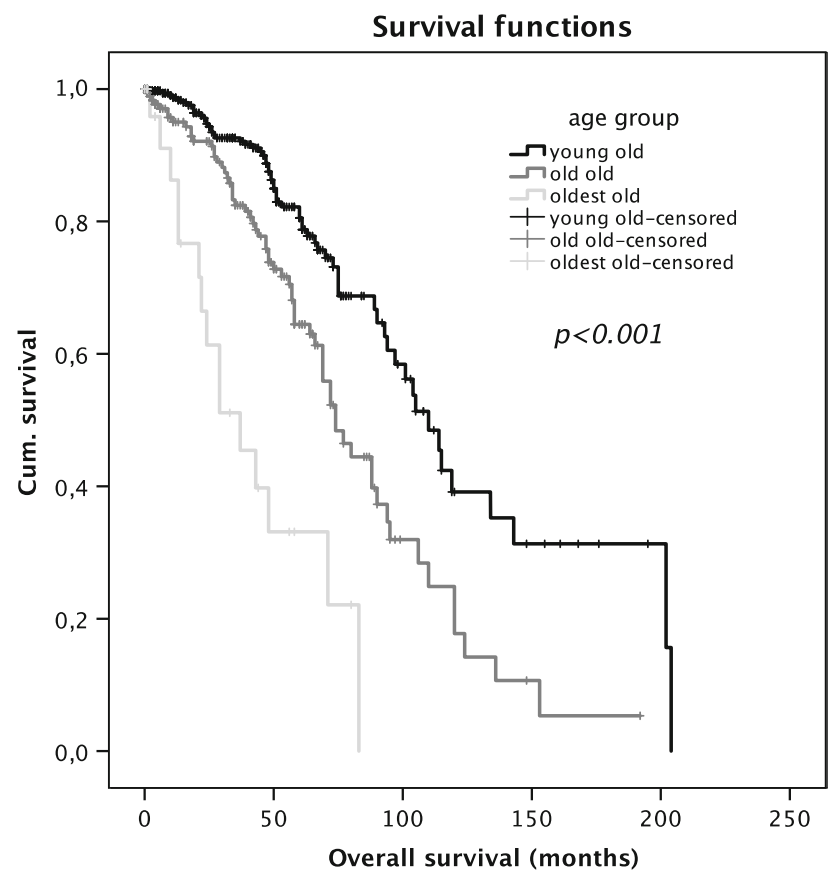

Fig. 2 Kaplan-Meier curves in the Vienna retrospective cohort of elderly breast cancer patients: overall survival according to age. $p$ values are according to the log-rank test
The presence of renal impairment was significantly associated with shorter median OS (95 months (95\% CI, 95.85-119.36) versus 53 months (95\% CI, 52.48-81.85; $p<0.001$, log-rank test)) (Fig. 4). All other comorbidities did not present with a significant impact on OS prognosis.

In the Cox proportional hazard model, the triple-negative subtype had a significantly better outcome in terms of OS even after correction for grade, nodal status, renal impairment, and age. Table 3 summarizes the results of the multivariate analysis of the total population as well as triple-negative cohort.

Finally, diagnosis of metachronous metastases (HR 7.7; $95 \%$ CI 5.2-11.4; $p<0.001)$ as well as development of BM (HR 3.5; $95 \%$ CI 1.9-6.4; $p<0.001$ ) had a significant impact on OS prognosis as entered in a time-dependent covariate cox regression model.

\section{Discussion}

Different BC subtypes-luminal A and B, normal- and basal-like as well as HER2-positive-have been defined on the basis of divergent gene expression patterns. It was shown that these subtypes have a significant impact on clinical prognosis. In daily clinical practice, breast cancer subtypes are usually classified as luminal, triple-negative, and HER2-positive as defined by immunohistochemistry and analysis of $H E R 2 / n e u$ gene amplification.

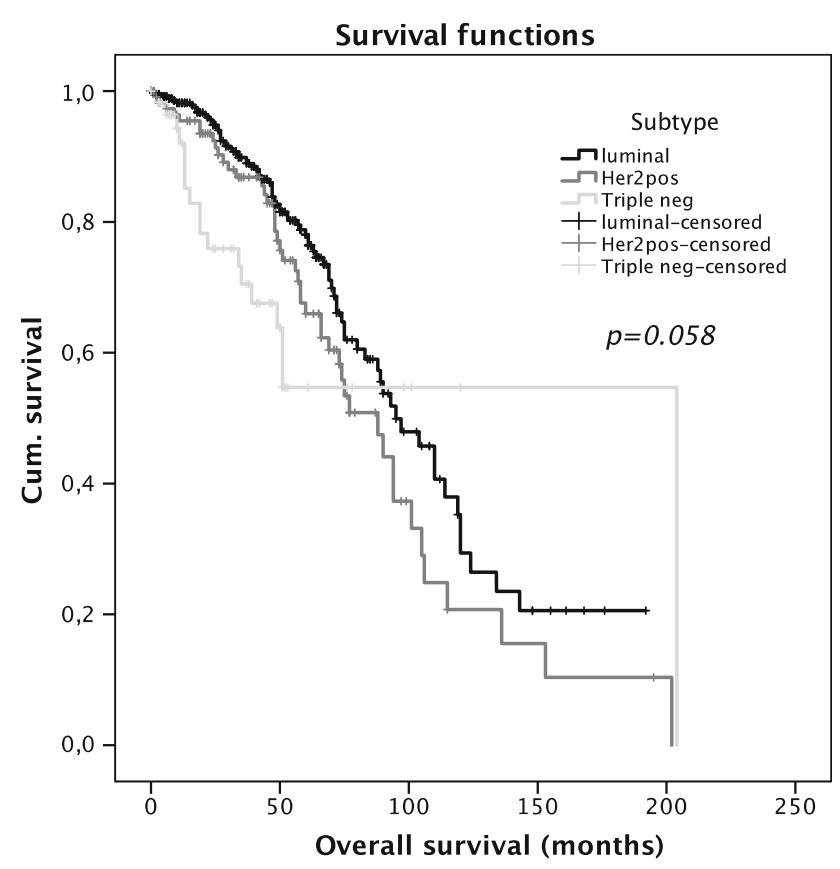

Fig. 3 Kaplan-Meier curves in the Vienna retrospective cohort of elderly breast cancer patients: overall survival according to subtype. $p$ values are according to the log-rank test 


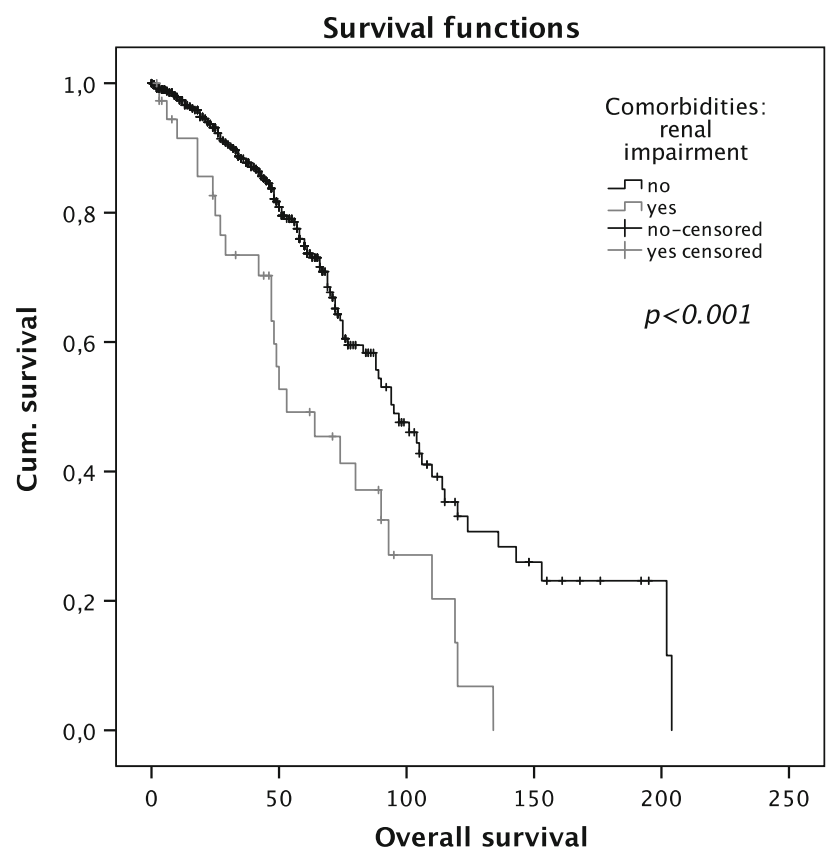

Fig. 4 Kaplan-Meier curves in the Vienna retrospective cohort of elderly breast cancer patients: overall survival according to renal impairment. $p$ value according to the log-rank test

Henceforth, little is known about the impact of these subtypes on prognosis specifically in elderly patients. Therefore, we investigated survival outcomes in different breast cancer subtypes in an elderly BC cohort of 571 patients. To our best knowledge, this is the first singlecentre cohort of this size focusing on elderly BC patients and the specific role of disease subtypes.

Luminal breast cancer is associated with a more favourable outcome as compared to basal-like and HER2enriched subtypes across all age groups [20-22]. Still, BC survival rates are comparatively lower for women $<40$ years of age than for older women across all histological subtypes and stages [23]. Many studies have confirmed the increased proportion of ER/PR-negativity, HER2-overexpression, and high-grade tumours in young women with breast cancer $[24,25]$. Therefore, a higher rate of aggressive tumour subtypes may account for the worse outcome in patients of young age.
In contrast to younger patients, the most frequently observed subtype in this large cohort of elderly patients was by far the luminal subtype followed by HER2-positive and triple-negative disease. These data are well in line with other studies showing that the incidence of luminal BC is increasing with age [26, 27]. Still, unfavourable tumour phenotypes such as HER2-positive and TNBC are observed in patients $\geq 70$ years of age as well [12], necessitating specific age-adapted treatment approaches. In this study, we analysed for factors significantly associated with survival outcome in an elderly BC cohort with a special emphasis on comorbidities and BM in order to improve clinical risk assessment.

OS was 93 months in the entire population and $20.1 \%$ experienced disease relapse at a median follow-up of 38 months. Data from a randomized study of standard adjuvant chemotherapy or capecitabine in elderly breast cancer patients reported comparable recurrence rates at 3-year follow-up [28], thereby strengthening the validity of our data.

Of note, the highest recurrence rate in this study was observed in the HER2-positive group, indicating that despite the availability of anti-HER2 therapy, this subtype remains the most aggressive phenotype in elderly $\mathrm{BC}$ patients. In line with that assumption, HER2-positive BC patients had the numerically shortest OS (88 months) and highest incidence of $\mathrm{BM}$ as well $(7.6 \%)$, thus indicating that novel treatment strategies must be sought in this highrisk population.

Indeed, BM are a devastating complication of breast cancer; overall, only 17 patients $(3 \%)$ of this elderly population were diagnosed with BM during their respective course of disease, thereby suggesting that BM are less commonly observed in elderly patients. As outlined above, the rate of HER2-positivity was significantly higher in patients diagnosed with $\mathrm{BM}$ as compared to elderly patients without BM (52.9 vs. $19.9 \% ; p=0.001$ ); of note, there was no difference in the rate of TNBC in patients with or without BM (11.8 vs. $10.3 \% ; p>0.05$ ). In addition, BM were significantly more often observed in the HER2-positive group as compared to other subtypes (7.6 \% in patients with HER2-positive tumours vs. $3.4 \%$
Table 3 Factors associated with overall survivalmultivariate analysis

\begin{tabular}{lrlllllll}
\hline & \multicolumn{3}{l}{ Total population } & & \multicolumn{2}{l}{ TNBC } \\
\cline { 2 - 3 } & \multicolumn{1}{c}{$p$} & Hazard ratio & $95 \%$ CI & & $p$ & Hazard ratio & $95 \%$ CI \\
\hline Grade & 0.010 & 1.536 & $1.107-2.130$ & & 0.048 & 3.179 & $1.012-9.983$ \\
Nodal status & $<0.001$ & 1.201 & $1.085-1.329$ & & 0.022 & 1.394 & $1.048-1.855$ \\
Renal impairment & 0.023 & 1.751 & $1.081-2.837$ & & 0.021 & 18.589 & $1.550-222.977$ \\
Adjuvant chemotherapy & 0.516 & 1.153 & $0.75-1.775$ & & 0.949 & 1.04 & $0.31-3.493$ \\
Age group & $<0.001$ & 2.446 & $1.798-3.326$ & & 0.001 & 5.634 & $2.096-15.145$ \\
TNBC & 0.020 & 1.941 & $1.112-3.387$ & - & - & - \\
\hline
\end{tabular}


in TNBC and $1.5 \%$ in luminal breast cancer; $p=0.003)$. Therefore, despite the well-known high incidence of BM in younger TNBC patients [29], elderly patients with TNBC apparently were not at increased risk for developing BM and these data suggest that development of BM in elderly may be exclusively linked to HER2positivity.

Of note, Königsberg et al. [30] also reported a-albeit non-significantly-lower rate of BM in an elderly as compared to a younger TNBC population (9.8 vs. $5.5 \%$; n.s.). In line with those data, other publications suggested better outcomes in elderly TNBC patients in general [3133], hinting at a distinct biology of triple-negative disease in older patients. Pointing to the same direction, TNBC was associated with numerically longest OS in our study.

To little surprise, age at primary diagnosis was shown to have the greatest influence on OS, which can be attributed to alternative causes of death with increasing age [34]. In an analysis of four large trials of women with $\mathrm{BC}$ receiving adjuvant chemotherapy, OS was shorter as age increased and older patients were more likely to die of non-breast cancerrelated causes [35], indicating the importance of comorbidities. In our cohort, cardiovascular disease was the most frequently observed comorbidity and was recorded in 382 $(66.9 \%)$ of patients; still, no significant association with survival outcome was observed. Of note, in patients with cardiovascular disease, HER2-positivity had no significant influence on survival indicating that the dismal prognosis of this subtype in our study is rather due to underlying aggressive tumour biology of HER2-positive disease than a result of undertreatment with anti-HER2 therapy in patients with pre-existing cardiac conditions (data not shown). Renal impairment, in contrast, had a significant influence on OS and occurred most frequently in patients between 75 and 84 years. In a population-based sample of 1800 postmenopausal patients renal failure among others was also shown to be significant in predicting early mortality and its prevalence significantly increased with age [36]. Taken together, these data suggest that renal impairment is a major factor that needs to be taken into account when assessing treatment strategies for elderly BC patients.

In the multivariate analysis of OS, grading, nodal status, renal impairment, age as well as the triple-negative subtype retained statistical significance. To correct for other factors influencing the relatively good prognosis of TNBC in this cohort of elderly patients, we performed a multivariate analysis also within this subtype. All factors significantly associated with OS on univariate analysis remained significant also within the Cox regression model with the exemption of adjuvant chemotherapy; this indicates that the decision for systemic therapy in elderly TNBC patients has to be carefully considered as only a limited number of elderly women with TNBC may derive any benefit from adjuvant treatment. Due to the retrospective design of this analysis, however, prospective studies are required in order to draw firm conclusions.

Although this is relatively large study, three major limitations must be mentioned. First, this is a monocentric analysis; second, the retrospective design; finally, the lack of any comprehensive geriatric assessment in these patients. Geriatric assessments should be considered an integral part of cancer care in elderly patients as it may help in defining optimal age- and risk-adapted therapy [37]. Girre et al. [38] reported that $39 \%$ of patients had their treatment plan changed after geriatric assessment; in another study, some patients with breast cancer underwent surgery for which they were originally considered unfit [39]. Implementation of comprehensive geriatric assessment (CGA) evidently improves compliance, treatment tolerability, quality of life (QoL), and survival in an elderly population [40].

In summary, to our best knowledge, this is the first analysis of breast cancer subtypes and their prognostic impact on clinical course and BM incidence specifically in elderly breast cancer patients. Despite the weaknesses of a monocentric retrospective design, we were able to establish a clear correlation of HER2-status, recurrence rate, and BM incidence in a large population of 571 elderly breast cancer patients. This suggests that similar to younger patients, elderly HER2-positive patients should be considered at high risk for developing cerebral as well as non-cerebral metastases, while the risk may be lower in TNBC. Further research should therefore focus on a hypothetically distinct biology of TNBC in an elderly BC population as well as on the improvement of treatment strategies in HER2-positive disease in elderly. Whether the adverse prognosis of HER2-positive disease in elderly patients can be overcome by novel (and potentially less toxic) treatment approaches such as T-DM1 awaits further clarification.

Acknowledgments Open access funding provided by Medical University of Vienna. This study was performed within the Ph.D. thesis project of Elisabeth Bergen in the Ph.D. program 'Clinical Neuroscience (CLINS)' at the Medical University Vienna.

Source of funding This work was supported by the research budget of the Medical University of Vienna.

\section{Compliance with ethical standards}

Conflict of interest The authors have declared no conflicts of interest.

Open Access This article is distributed under the terms of the Creative Commons Attribution-NonCommercial 4.0 International License (http://creativecommons.org/licenses/by-nc/4.0/), which permits any noncommercial use, distribution, and reproduction in any medium, provided you give appropriate credit to the original author(s) and the source, provide a link to the Creative Commons license, and indicate if changes were made. 


\section{References}

1. Boyle P, Ferlay J (2005) Cancer incidence and mortality in Europe, 2004. Ann Oncol 16:481-488

2. Trimble EL, Carter CL, Cain D, Freidlin B, Ungerleider RS, Friedman MA (1994) Representation of older patients in cancer treatment trials. Cancer 74:2208-2214

3. Aapro MS, Kohne CH, Cohen HJ, Extermann M (2005) Never too old? Age should not be a barrier to enrollment in cancer clinical trials. Oncologist 10:198-204

4. Extermann M, Overcash J, Lyman GH, Parr J, Balducci L (1998) Comorbidity and functional status are independent in older cancer patients. J Clin Oncol 16:1582-1587

5. Monfardini S (2004) Evaluation of renal function in elderly cancer patients. Ann Oncol 15:183-184

6. Crivellari D, Bonetti M, Castiglione-Gertsch M, Gelber RD, Rudenstam CM, Thurlimann B, Price KN, Coates AS, Hurny C, Bernhard J, Lindtner J, Collins J, Senn HJ, Cavalli F, Forbes J, Gudgeon A, Simoncini E, Cortes-Funes H, Veronesi A, Fey M, Goldhirsch A (2000) Burdens and benefits of adjuvant cyclophosphamide, methotrexate, and fluorouracil and tamoxifen for elderly patients with breast cancer: the international breast cancer study group trial vii. J Clin Oncol 18:1412-1422

7. Egorin MJ (1993) Cancer pharmacology in the elderly. Semin Oncol 20:43-49

8. Baker SD, Grochow LB (1997) Pharmacology of cancer chemotherapy in the older person. Clin Geriatr Med 13:169-183

9. Rottlaender D, Scherner M, Schneider T, Erdmann E (2007) Polypharmacy, compliance and non-prescription medication in patients with cardiovascular disease in Germany. Dtsch Med Wochenschr 132:139-144

10. Diab SG, Elledge RM, Clark GM (2000) Tumor characteristics and clinical outcome of elderly women with breast cancer. J Natl Cancer Inst 92:550-556

11. Freyer G, Braud AC, Chaibi P, Spielmann M, Martin JP, Vilela G, Guerin D, Zelek L (2006) Dealing with metastatic breast cancer in elderly women: results from a French study on a large cohort carried out by the 'observatory on elderly patients'. Ann Oncol $17: 211-216$

12. Jenkins EO, Deal AM, Anders CK, Prat A, Perou CM, Carey LA, Muss HB (2014) Age-specific changes in intrinsic breast cancer subtypes: a focus on older women. Oncologist 19(10):1076-1083

13. Lin NU, Winer EP (2007) Brain metastases: the her2 paradigm. Clin Cancer Res 13:1648-1655

14. Sanna G, Franceschelli L, Rotmensz N, Botteri E, Adamoli L, Marenghi C, Munzone E, Cossu Rocca M, Verri E, Minchella I, Medici M, Catania C, Magni E, Goldhirsch A, Nole F (2007) Brain metastases in patients with advanced breast cancer. Anticancer Res 27:2865-2869

15. Berghoff A, Bago-Horvath Z, De Vries C, Dubsky P, Pluschnig U, Rudas M, Rottenfusser A, Knauer M, Eiter H, Fitzal F, Dieckmann K, Mader RM, Gnant M, Zielinski CC, Steger GG, Preusser M, Bartsch R (2012) Brain metastases free survival differs between breast cancer subtypes. Br J Cancer 106:440-446

16. Hammond ME, Hayes DF, Dowsett M, Allred DC, Hagerty KL, Badve S, Fitzgibbons PL, Francis G, Goldstein NS, Hayes M, Hicks DG, Lester S, Love R, Mangu PB, McShane L, Miller K, Osborne CK, Paik S, Perlmutter J, Rhodes A, Sasano H, Schwartz JN, Sweep FC, Taube S, Torlakovic EE, Valenstein P, Viale G, Visscher D, Wheeler T, Williams RB, Wittliff JL, Wolff AC (2010) American society of clinical oncology/college of american pathologists guideline recommendations for immunohistochemical testing of estrogen and progesterone receptors in breast cancer. J Clin Oncol 28:2784-2795
17. Wolff AC, Hammond ME, Schwartz JN, Hagerty KL, Allred DC, Cote RJ, Dowsett M, Fitzgibbons PL, Hanna WM, Langer A, McShane LM, Paik S, Pegram MD, Perez EA, Press MF, Rhodes A, Sturgeon C, Taube SE, Tubbs R, Vance GH, van de Vijver M, Wheeler TM, Hayes DF (2007) American society of clinical oncology/college of american pathologists guideline recommendations for human epidermal growth factor receptor 2 testing in breast cancer. J Clin Oncol 25:118-145

18. Anders CK, Deal AM, Miller CR, Khorram C, Meng H, Burrows E, Livasy C, Fritchie K, Ewend MG, Perou CM, Carey LA (2011) The prognostic contribution of clinical breast cancer subtype, age, and race among patients with breast cancer brain metastases. Cancer 117:1602-1611

19. Duan XF, Dong NN, Zhang T, Li Q (2013) The prognostic analysis of clinical breast cancer subtypes among patients with liver metastases from breast cancer. Int J Clin Oncol 18:26-32

20. Engstrom MJ, Opdahl S, Hagen AI, Romundstad PR, Akslen LA, Haugen OA, Vatten LJ, Bofin AM (2013) Molecular subtypes, histopathological grade and survival in a historic cohort of breast cancer patients. Breast Cancer Res Treat 140:463-473

21. Lobbezoo DJ, van Kampen RJ, Voogd AC, Dercksen MW, van den Berkmortel F, Smilde TJ, van de Wouw AJ, Peters FP, van Riel JM, Peters NA, de Boer M, Borm GF, Tjan-Heijnen VC (2013) Prognosis of metastatic breast cancer subtypes: the hormone receptor/her2-positive subtype is associated with the most favorable outcome. Breast Cancer Res Treat 141:507-514

22. Jenkins EO, Deal AM, Anders CK, Prat A, Perou CM, Carey LA, Muss HB (2014) Age-specific changes in intrinsic breast cancer subtypes: a focus on older women. Oncologist 19:1076-1083

23. Anders CK, Johnson R, Litton J, Phillips M, Bleyer A (2009) Breast cancer before age 40 years. Semin Oncol 36:237-249

24. Anders CK, Hsu DS, Broadwater G, Acharya CR, Foekens JA, Zhang Y, Wang Y, Marcom PK, Marks JR, Febbo PG, Nevins JR, Potti A, Blackwell KL (2008) Young age at diagnosis correlates with worse prognosis and defines a subset of breast cancers with shared patterns of gene expression. J Clin Oncol 26:3324-3330

25. Collins LC, Marotti JD, Gelber S, Cole K, Ruddy K, Kereakoglow S, Brachtel EF, Schapira L, Come SE, Winer EP, Partridge AH (2012) Pathologic features and molecular phenotype by patient age in a large cohort of young women with breast cancer. Breast Cancer Res Treat 131:1061-1066

26. Rauh C, Gass P, Heusinger K, Haeberle L, Jud SM, Hein A, Loehberg CR, Lux MP, Wachter DL, Heimrich J, Strehl JD, Haller F, Hartmann A, Schulz-Wendtland R, Fiessler C, Beckmann MW, Fasching PA, Poehls U (2014) Association of molecular subtypes with breast cancer risk factors: a case-only analysis. Eur J Cancer Prev 24(6):484-490

27. de Kruijf EM, Bastiaannet E, Ruberta F, de Craen AJ, Kuppen PJ, Smit VT, van de Velde CJ, Liefers GJ (2014) Comparison of frequencies and prognostic effect of molecular subtypes between young and elderly breast cancer patients. Mol Oncol 8:1014-1025

28. Muss HB, Berry DA, Cirrincione CT, Theodoulou M, Mauer AM, Kornblith AB, Partridge AH, Dressler LG, Cohen HJ, Becker HP, Kartcheske PA, Wheeler JD, Perez EA, Wolff AC, Gralow JR, Burstein HJ, Mahmood AA, Magrinat G, Parker BA, Hart RD, Grenier D, Norton L, Hudis CA, Winer EP (2009) Adjuvant chemotherapy in older women with early-stage breast cancer. N Engl J Med 360:2055-2065

29. Heitz F, Harter P, Lueck HJ, Fissler-Eckhoff A, Lorenz-Salehi F, Scheil-Bertram S, Traut A, du Bois A (2009) Triple-negative and her2-overexpressing breast cancers exhibit an elevated risk and an earlier occurrence of cerebral metastases. Eur $\mathrm{J}$ Cancer 45:2792-2798

30. Konigsberg R, Pfeiler G, Klement T, Hammerschmid N, Brunner A, Zeillinger R, Singer C, Dittrich C (2012) Tumor characteristics and 
recurrence patterns in triple negative breast cancer: a comparison between younger $(<65)$ and elderly $(>/=65)$ patients. Eur J Cancer 48:2962-2968

31. Thike AA, Iqbal J, Cheok PY, Chong AP, Tse GM, Tan B, Tan P, Wong NS, Tan PH (2010) Triple negative breast cancer: outcome correlation with immunohistochemical detection of basal markers. Am J Surg Pathol 34:956-964

32. Syed BM, Green AR, Nolan CC, Morgan DA, Ellis IO, Cheung KL (2014) Biological characteristics and clinical outcome of triple negative primary breast cancer in older women: comparison with their younger counterparts. PLoS ONE 9:e100573

33. Liedtke C, Hess KR, Karn T, Rody A, Kiesel L, Hortobagyi GN, Pusztai L, Gonzalez-Angulo AM (2013) The prognostic impact of age in patients with triple-negative breast cancer. Breast Cancer Res Treat 138:591-599

34. Ring A, Sestak I, Baum M, Howell A, Buzdar A, Dowsett M, Forbes JF, Cuzick J (2011) Influence of comorbidities and age on risk of death without recurrence: a retrospective analysis of the arimidex, tamoxifen alone or in combination trial. J Clin Oncol 29:4266-4272

35. Muss HB, Woolf S, Berry D, Cirrincione C, Weiss RB, Budman D, Wood WC, Henderson IC, Hudis C, Winer E, Cohen H, Wheeler J, Norton L (2005) Adjuvant chemotherapy in older and younger women with lymph node-positive breast cancer. JAMA 293:1073-1081
36. Yancik R, Wesley MN, Ries LA, Havlik RJ, Edwards BK, Yates JW (2001) Effect of age and comorbidity in postmenopausal breast cancer patients aged 55 years and older. JAMA 285:885-892

37. Hamaker ME, Seynaeve C, Wymenga AN, van Tinteren H, Nortier JW, Maartense E, de Graaf H, de Jongh FE, Braun JJ, Los M, Schrama JG, van Leeuwen-Stok AE, de Groot SM, Smorenburg CH (2014) Baseline comprehensive geriatric assessment is associated with toxicity and survival in elderly metastatic breast cancer patients receiving single-agent chemotherapy: results from the omega study of the dutch breast cancer trialists' group. Breast 23:81-87

38. Girre V, Falcou MC, Gisselbrecht M, Gridel G, Mosseri V, Bouleuc C, Poinsot R, Vedrine L, Ollivier L, Garabige V, Pierga JY, Dieras V, Mignot L (2008) Does a geriatric oncology consultation modify the cancer treatment plan for elderly patients? J Gerontol Ser A Biol Sci Med Sci 63:724-730

39. Stotter A, Tahir M, Pretorius R, Robinson T (2010) Experiences of a multidisciplinary elderly breast cancer clinic: using the right specialists, in the same place, with time. In: Reed M, Audisio R (eds) Management of breast cancer in older women

40. Pallis AG, Fortpied C, Wedding U, Van Nes MC, Penninckx B, Ring A, Lacombe D, Monfardini S, Scalliet P, Wildiers H (2010) Eortc elderly task force position paper: approach to the older cancer patient. Eur J Cancer 46:1502-1513 